\title{
Distribuição da comunidade de epífitas vasculares em sítios sob diferentes graus de perturbação na Floresta Nacional de Ipanema, São Paulo, Brasil
}

\author{
FERNANDO ANTONIO BATAGHIN ${ }^{1,3}$, FÁBIO DE BARROS ${ }^{2}$ e \\ JOSÉ SALATIEL RODRIGUES PIRES ${ }^{1}$
}

(recebido: 08 de abril de 2009; aceito: 26 de agosto de 2010

\begin{abstract}
Distribution of the community of vascular epiphytes in sites under different degrees of disturbance in the Ipanema National Forest, São Paulo, Brazil). Despite the importance of vascular epiphytes to indicate the degree of local conservation, there is little research on this subject. The present research was performed in the Ipanema National Forest, Iperó, São Paulo, Brazil, aiming to characterize the vascular epiphytic community, to analyze their vertical distribution and to analyze the correlation among different sites. Three sites were considered: RIA - remnant isolated/modified, FAB - advanced forest/border, and FAI - advanced forest/inside. On each site 90 assorted trees $(\mathrm{DBH} \geq 20 \mathrm{~cm})$ were sampled. Frequency, abundance and diversity parameters based on the occurrence of epiphytes in the strata and in the assorted trees were estimated. In the present survey 21 species belonging to 14 genera and six families were found. The Shannon index of diversity $\left(H^{\prime}\right)$ for the whole epiphytic community was 2.272 , the equability $(J)=0.713$ and Margalef's richness $(\mathrm{d})=2.467$. The richness and diversity of sites were: 18 species, $H^{\prime}=2.159, J=0.747$ and $\mathrm{d}=2.180$ for the RIA site, seven species, $H^{\prime}=1.270$, $J=0.652$ and $\mathrm{d}=1.017$ for the FAB site, and 13 species, $H^{\prime}=1.587, J=0.618$ and $\mathrm{d}=1.919$ for the FAI site. Although there are significant differences among RIA to FAB and FAI, there is no difference between FAB and FAI. This research highlights the influence of environmental changes over epiphytic communities and the importance of disturbed forest remnants or even isolated trees to sustain the vascular epiphytes.
\end{abstract}

Key words - Atlantic Forest, environmental change, phytosociology of epiphytes

RESUMO - (Distribuição da comunidade de epífitas vasculares em sítios sob diferentes graus de perturbação na Floresta Nacional de Ipanema, São Paulo, Brasil). Apesar da importância de epífitas vasculares em refletir o grau de preservação local, existem poucas pesquisas sobre o tema. Esta pesquisa foi desenvolvida na Floresta Nacional de Ipanema, Iperó, SP, e teve por objetivo caracterizar e analisar a comunidade epifítica vascular em sítios sob diferentes graus de perturbação. Foram determinados três sítios: RIA - remanescente isolado/alterado, FAB - floresta avançada/borda e FAI - floresta avançada/interior e, em cada sítio, foram amostrados 90 forófitos com DAP $\geq 20 \mathrm{~cm}$. Foram estimamos os parâmetros de freqüência, dominância e diversidade com base na ocorrência das epífitas nos estratos e nos forófitos. No levantamento foram encontradas 21 espécies, 14 gêneros e seis famílias. O índice de diversidade Shannon $\left(H^{\prime}\right)$ para toda a comunidade epifítica foi de 2,172, a equabilidade $(J)=0,713$ e a riqueza de Margalef $(\mathrm{d})=2,467$. A riqueza e a diversidade dos sítios foram de: 18 espécies, $H^{\prime}=2,159$, $J=0,747$ e $\mathrm{d}=2,180$ para o Sítio RIA; sete espécies, $H^{\prime}=1,270, J=0,652$ e d $=1,017$ para o Sítio FAB; e 13 espécies, $H^{\prime}=1,587, J=0,618$ e d = 1,919 para o Sítio FAI. Embora existam diferenças significativas entre os sítios RIA e FAB, e entre os sítios RIA e FAI, não houve variação significativa entre os sítios FAB e FAI. Essa pesquisa destaca a influência das alterações ambientais sobre as comunidades epifíticas e a importância de remanescentes florestais alterados ou mesmo árvores isoladas para a manutenção das epífitas vasculares.

Palavras-chave - alterações ambientais, fitossociologia de epífitas, Mata Atlântica

\section{Introdução}

A Floresta Nacional de Ipanema (Flona de Ipanema), em Iperó, a 125 quilômetros da capital paulista, foi criada em 20 de maio de 1992, por meio do Decreto 530, para

1. Universidade Federal de São Carlos, Centro de Ciências Biológicas e da Saúde, Departamento de Hidrobiologia, Via Washington Luiz, km 235, Monjolinho, 13565-905 São Carlos, SP, Brasil.

2. Instituto de Botânica, Núcleo de Pesquisa em Plantas Ornamentais, Caixa Postal 3005, 01031-970 São Paulo, SP, Brasil.

3. Autor para correspondência: bataghin@ufscar.br preservar e conservar um dos maiores fragmentos de Mata Atlântica do interior do Estado de São Paulo, bem como áreas de cerrado, várzea, ecossistemas associados e sua diversidade biológica (Ibama 2003).

No contexto da paisagem regional, a Flona de Ipanema é uma área extensa de Floresta Estacional Semidecidual, remanescente de uma vegetação totalmente fragmentada, e com um histórico de perturbação que data quase da época do descobrimento do Brasil. Os primeiros registros datam de 1589, quando os bandeirantes chegaram à área iniciando a extração de minério de ferro. 
Em 1810, Dom João VI decretou a criação da Fábrica de Ferro Ipanema, a primeira siderúrgica brasileira, que se manteve ativa na Flona de Ipanema até 1895 . Na região mais montanhosa da Flona, denominada Serra de Araçoiaba, em 1926 começou a extração de apatita para fabricação de superfosfato e em 1950 deu-se inicio à extração de calcário para a produção de cimento. Nesta última ocasião, a Flona encontrava-se sob administração do Ministério da Agricultura, que realizava ensaios com sementes e com máquinas agrícolas. Em 1986 a Marinha do Brasil instalou, em uma área da Flona, seu centro de pesquisas para desenvolver reatores nucleares para submarinos (Aramar), um complexo que ocupa 78 ha da área (Ibama 2003).

O papel da biodiversidade no funcionamento de ecossistemas tem recebido crescente tratamento teórico (Tilman 1988, Grime 2001, Callaway et al. 2002, Naeem 2003, Pires et al. 2005), entretanto ainda não é clara a magnitude da importância da biodiversidade em relação às outras partes componentes do ecossistema, nem $o$ quanto este grau de importância varia de um para outro ecossistema (Tilman \& Lehman 2001).

As epífitas são plantas que se estabelecem diretamente sobre o tronco, galhos, ramos ou sobre as folhas das árvores, sem a emissão de estruturas haustoriais, e as plantas que as sustentam são denominadas forófitos (Benzing 1990). Dentre os principais estudos brasileiros sobre a comunidade epifítica vascular, realizados em Floresta Estacional Semidecidual, destacam-se os de Aguiar et al. (1981), Rogalski \& Zanin (2003) e Giongo \& Waechter (2004) no Rio Grande do Sul, Borgo et al. (2002) no Paraná e Dislich \& Mantovani (1998) na cidade de São Paulo.

A ocupação das epífitas nas árvores hospedeiras (forófitos) parece estar relacionada a fatores abióticos como luz, umidade e substrato (Fontoura 2001), e com o estágio sucessional da floresta (Kersten \& Kuniyoshi 2009). Regionalmente, a distribuição de chuvas ao longo do ano parece ser mais importante para o sucesso das epífitas que o total anual de chuva na área (Gentry \& Dodson 1987).

Em função das características fisiológicas e nutricionais, as epífitas têm um papel fundamental em estudos sobre a interferência antrópica no ambiente, uma vez que elas, muitas vezes, utilizam-se da umidade atmosférica, absorvendo-a diretamente pelas folhas ou talos, o que as torna mais expostas à ação dos poluentes (Aguiar et al. 1981). As epífitas podem refletir o grau de preservação local, uma vez que alguns grupos são menos tolerantes às variações ambientais decorrentes da devastação e das queimadas (Sota 1971). Analisar e correlacionar fatores que regem a dinâmica da floresta é fundamental para o entendimento dos mecanismos mantenedores da biodiversidade.

Este trabalho teve por objetivo caracterizar a comunidade epifítica vascular da Floresta Nacional de Ipanema, que ocorre em diferentes sítios da Floresta Estacional Semidecidual, analisando a distribuição e os padrões de distribuição vertical, bem como a existência de correlação na riqueza e abundância das epífitas entre os diferentes sítios estudados, além de testar a hipótese de que a comunidade epifítica vascular difere entre os sítios, devido aos diferentes tipos de ambientes que esses representam.

\section{Material e métodos}

A Floresta Nacional de Ipanema (figura 1), possui $5.179,93$ hectares e está localizada entre as Latitudes $23^{\circ} 21^{\prime}$, e $23^{\circ} 30^{\prime}$ S e Longitudes $47^{\circ} 30^{\prime}$ e $47^{\circ} 45^{\prime}$ W, nos Município de Iperó, Capela do Alto e Araçoiaba da Serra, na região sudeste do Estado de São Paulo (Fávero et al. 2004).

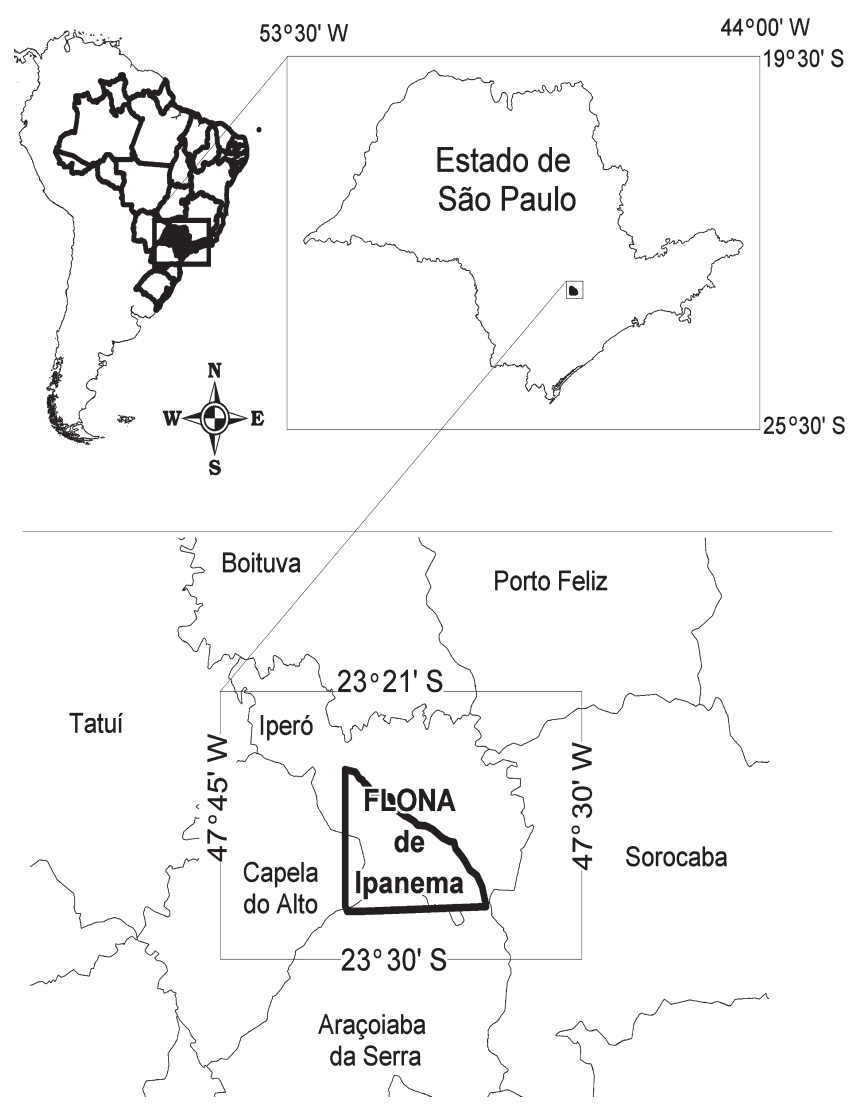

Figura 1. Localização da Floresta Nacional de Ipanema (Flona de Ipanema), Iperó, São Paulo, Brasil.

Figure 1. Location of the Ipanema National Forest, Iperó, São Paulo State, Brazil. 
O Trópico de Capricórnio passa pela parte sul da Floresta Nacional de Ipanema, caracterizando a zona de transição, de tropical para temperada. Segundo o sistema de Koeppen, apresenta condições climáticas tipo $\mathrm{Cfa}$ - subtropical quente, constantemente úmido, com inverno menos seco, ao sul, limitando com Cwa - subtropical quente, com inverno mais seco, ao norte (Ibama 2003).

Foi determinado um sítio amostral em cada tipo de ambiente, a saber: Remanescente isolado/alterado (RIA); Floresta avançada/borda (FAB); e Floresta avançada/ interior (FAI). Em cada sítio foram demarcadas parcelas de $10 \times 15 \mathrm{~m}$ até serem amostrados 90 forófitos; cada sítio teve a extensão estabelecida em 45 metros (três parcelas). O sítio denominado de Remanescente isolado/alterado $\left(23^{\circ} 25^{\prime} 47^{\prime \prime} \mathrm{S}\right.$, $47^{\circ} 35^{\prime} 47^{\prime \prime} \mathrm{W}$ ) foi caracterizado como um trecho de vegetação em que ocorreu e vem ocorrendo a supressão (manejo) do estrado herbáceo-arbustivo, restando apenas indivíduos de maior porte (árvores com DAP $>30 \mathrm{~cm}$ ), geralmente isolados, mas onde, em alguns casos, as copas formam uma cobertura contínua do dossel. Para o sítio Floresta avançada/borda $\left(23^{\circ} 24^{\prime} 58^{\prime \prime} \mathrm{S}, 4^{\circ} 37^{\prime} 13^{\prime \prime} \mathrm{W}\right)$, caracterizada como uma área de floresta secundária em estágio avançado de regeneração, foram adentrados 15 metros na floresta e instalada a primeira parcela, e para o sítio Floresta avançada/interior $\left(23^{\circ} 25^{\prime} 43^{\prime \prime} \mathrm{S}\right.$, 47037'19” W), também caracterizado como uma área de floresta secundária em estágio avançado de regeneração, foram adentrados 300 metros a partir da borda externa e instalada a primeira parcela. Em cada sítio foram amostrados 90 forófitos, perfazendo 270 forófitos nos três sítios.

Foram realizadas visitas entre setembro de 2007 e agosto de 2008 amostrando as epífitas vasculares que se encontravam sobre indivíduos arbóreos com DAP (diâmetro à altura do peito) $\geq 20 \mathrm{~cm}$. Cada forófito foi marcado e numerado com placa de alumínio, e anotados os dados taxonômicos, o DAP, e a altura.

$\mathrm{Na}$ análise dos indivíduos epifíticos vasculares foi utilizada a metodologia proposta por Kersten \& Silva (2002). O material botânico dos epífitos vasculares e dos forófitos foi processado segundo as técnicas de herborização apresentadas em Fidalgo \& Bononi (1989) e depositado no herbário da Universidade Federal de São Carlos - Campus Sorocaba (UFSCar-CS). A identificação foi feita com base em bibliografia especializada para cada família vegetal amostrada, por comparação com material previamente identificado e por consulta a especialistas. Os nomes das espécies foram verificados nos sites especializados (www. tropicos.org e/ou www.kew.org.uk/epic) e em publicações taxonômicas, utilizando-se as abreviaturas dos autores sugeridas por Brummitt \& Powell (1992).

As espécies epifíticas foram classificadas em categorias ecológicas, de acordo com sua relação com o forófito (Benzing 1990, Kersten \& Silva 2001) e foi registrada, para cada espécie, sua(s) posição(ões) no forófito (estratos) segundo as categorias sugeridas por Kersten \& Silva (2002), sendo elas: 1 = fuste baixo (até $1,3 \mathrm{~m}$ de altura); 2 = fuste alto (de 1,31 m até a base da copa); 3 = copa (Kersten \& Silva 2002).
Foram calculadas as freqüências absolutas de ocorrência nos estratos (FAr) e nos indivíduos forofíticos (FAi). O valor de importância epifítico (VIE) foi calculado com base nas notas atribuídas às epífitas, a saber: 1) um ou poucos indivíduos isolados; 2) agrupamentos mais extensos ou diversos indivíduos isolados; 3) abundante e formando, em muitos casos, uma cobertura quase contínua sobre o forófito. Foram empregadas as fórmulas sugeridas por Waechter (1998) e modificadas por Kersten \& Silva (2001): FAr $=\left(\mathrm{nr} \mathrm{na}^{-1}\right) 100$; $\mathrm{FAi}=\left(\mathrm{ni} \mathrm{nt}^{-1}\right) 100 ; \quad \mathrm{VIE}=\left[\mathrm{vt}\left(\sum \mathrm{vt}\right)^{-1}\right] \quad 100$, nas quais $\mathrm{nr}=$ número de regiões com ocorrência da espécie epifítica; na $=$ número total de regiões amostradas; $\mathrm{ni}=$ número de indivíduos com ocorrência da espécie; $\mathrm{nt}$ = número total de indivíduos; $\mathrm{vt}=$ somatória das notas obtidas pela espécie.

Foi calculada a nota média dada às espécies nos estratos, exprimindo sua abundância média sobre os forófitos. Desta forma, uma espécie que tenha obtido média superior a 2 ocupa sempre grandes áreas do forófito e outra, com média próxima ou igual a 1, apresenta-se, geralmente, pouco expressiva sobre os indivíduos arbóreos. Foi calculado, ainda, o valor absoluto (VA), uma estimativa da abundância com base na somatória das notas das espécies epifíticas nos estratos e forófitos.

Foram estimados os parâmetros de diversidade e riqueza utilizando os índices de diversidade de Shannon $\left(H^{\prime}\right)$ e riqueza de Margalef (d). Para análise da similaridade entre os sítios RIA, FAB e FAI, com base nos táxons de epífitos vasculares, foi realizada uma análise de agrupamentos, utilizando como medida de distância o coeficiente de similaridade de Jaccard. Além disso, foram aplicados os testes T (Student) e Kolmogorov-Smirnov (Magurran 1988) sobre o VA das espécies epifíticas para avaliar as diferenças entre os sítios RIA, FAB e FAI. Foi elaborado o diagrama de Whittaker com os valores de importância epifítica (VIE) para ilustrar a distribuição da abundância entre as espécies nos sítios estudados.

\section{Resultados}

$\mathrm{Na}$ área estudada foram registradas 21 espécies epifíticas, pertencentes a 14 gêneros e seis famílias. O índice de Shannon para os três sítios foi de $H^{\prime}=2,172$, a equabilidade $J=0,713$ e o índice de riqueza de Margalef (d) foi de 2,467. A distribuição das espécies epifíticas, segundo as categorias ecológicas de relação com o forófito, evidenciou o predomínio de holoepífitos característicos com 14 espécies (67\%), enquanto os holoepífitos facultativos foram representados por cinco espécies $(24 \%)$ e os holoepífitos acidentais por duas espécies (9\%) (tabela 1).

As espécies que apresentaram maior importância, considerando todos os sítios na área de estudo, foram: Tillandsia tricholepis (Bromeliaceae) com valor de importância epifítica (VIE) de 19,9 e nota média de 1,90 , tendo ocorrido em $60 \%$ dos forófitos e $43 \%$ dos 
Tabela 1. Espécies de epífitas vasculares da Floresta Nacional de Ipanema, SP, classificadas segundo o valor de importância epifítica. ( $\mathrm{CE}=$ categoria ecológica; HLC = holoepífito característico; HLF = holoepífito facultativo; HLA = holoepífito acidental; $\mathrm{PF}=$ posição no forófito; 1 = fuste baixo; 2 = fuste alto; 3 = copa; $\mathrm{nr}=$ número absoluto de ocorrências nos estratos; $\mathrm{FAr}=$ freqüência absoluta nos estratos; $\mathrm{ni}=$ número absoluto de ocorrências nos indivíduos forofíticos; $\mathrm{FAi}=$ freqüência absoluta nos indivíduos forofíticos; vt = valor total; soma das estimativas de abundância; VIE = valor de importância epifítico; nota $=$ nota média obtida).

Table 1. Vascular epiphytes from the Ipanema National Forest, São Paulo state, ordered by epiphytic importance value. $(\mathrm{CE}=$ ecological category; $\mathrm{HLC}=$ characteristic holoepiphyte; $\mathrm{HLF}=$ facultative holoepiphyte; HLA = accidental holoepiphyte; $\mathrm{PF}=$ position in the host tree; $1=$ low trunk; $2=$ high trunk; $3=$ capony; $\mathrm{nr}=$ absolute number occurrence in the strata; $\mathrm{FAr}=$ absolute frequency in the strata; $\mathrm{ni}=$ absolute number of occurrences in individual phorophytes; $\mathrm{FAi}=\mathrm{absolute}$ frequency in individual phorophytes; $\mathrm{vt}=$ total value, sum of estimates of abundance; $\mathrm{VIE}=$ epiphytic importance value; nota $=$ average score).

\begin{tabular}{lccccccccc}
\hline Espécies & CE & PF & nr & FAr & ni & FAi & vt & VIE & nota \\
\hline Tillandsia tricholepis Baker & HLC & $1 ; 2 ; 3$ & 348 & 43.0 & 162 & 60.0 & 661 & 19.9 & 1.90 \\
Tillandsia recurvata (L.) L. & HLC & $1 ; 2 ; 3$ & 335 & 41.4 & 153 & 56.7 & 652 & 19.6 & 1.95 \\
Pleopeltis pleopeltifolia (Raddi) Alston & HLC & $1 ; 2 ; 3$ & 299 & 36.9 & 153 & 56.7 & 622 & 18.7 & 2.08 \\
Pleopeltis squalida (Vell.) de la Sota & HLC & $1 ; 2 ; 3$ & 142 & 17.5 & 54 & 20.0 & 343 & 10.3 & 2.42 \\
Tillandsia stricta Sol. ex Sims & HLC & $1 ; 2 ; 3$ & 158 & 19.5 & 81 & 30.0 & 280 & 8.4 & 1.77 \\
Rhipsalis cereuscula Haw. & HCL & $1 ; 2 ; 3$ & 115 & 14.2 & 76 & 28.1 & 278 & 8.4 & 2.42 \\
Epiphyllum phyllanthus (L.) Haw. & HLC & $1 ; 2 ; 3$ & 76 & 9.4 & 45 & 16.7 & 146 & 4.4 & 1.92 \\
Microgramma squamulosa (Kaulf.) de la Sota & HLC & $1 ; 2 ; 3$ & 60 & 7.4 & 29 & 10.7 & 132 & 4.0 & 2.20 \\
Lepismium warmingianum (K. Schum.) Barthlott & HLC & $1 ; 2 ; 3$ & 26 & 3.2 & 16 & 5.9 & 51 & 1.5 & 1.96 \\
Lepismium cruciforme (Vell.) Miq. & HLC & $1 ; 2 ; 3$ & 15 & 1.9 & 11 & 4.1 & 36 & 1.1 & 2.40 \\
Rhipsalis teres (Vell.) Steud. & HLC & $1 ; 2 ; 3$ & 14 & 1.7 & 11 & 4.1 & 36 & 1.1 & 2.57 \\
Cereus alacriportanus Pfeiff. & HLF & $1 ; 2 ; 3$ & 19 & 2.3 & 10 & 3.7 & 34 & 1.0 & 1.79 \\
Aechmea distichantha Lem. & HLF & $1 ; 2 ; 3$ & 10 & 1.2 & 7 & 2.6 & 13 & 0.4 & 1.30 \\
Lepismium lumbricoides (Lem.) Barthlott & HLC & $1 ; 2$ & 5 & 0.6 & 4 & 1.5 & 8 & 0.2 & 1.60 \\
Epidendrum sp. & HLC & $1 ; 2$ & 5 & 0.6 & 4 & 1.5 & 6 & 0.2 & 1.20 \\
Philodendron bipinnatifidum Schott ex Endl. & HLF & $1 ; 2 ; 3$ & 7 & 0.9 & 6 & 2.2 & 8 & 0.2 & 1.14 \\
Tradescantia albiflora Kunth & HLA & 1 & 2 & 0.2 & 2 & 0.7 & 4 & 0.1 & 2.00 \\
Aechmea bromeliifolia Baker ex Benth. \& Hook. & HLC & 1 & 1 & 0.1 & 1 & 0.4 & 2 & 0.1 & 2.00 \\
Aechmea apocalyptica Reitz & HLF & 2 & 1 & 0.1 & 1 & 0.4 & 2 & 0.1 & 2.00 \\
Anthurium sp. & HLF & $1 ; 2$ & 2 & 0.2 & 2 & 0.7 & 3 & 0.1 & 1.50 \\
Oeceoclades maculata (Lindl.) Lindl. & HLA & 2 & 2 & 0.2 & 2 & 0.7 & 4 & 0.1 & 2.00 \\
\hline
\end{tabular}

estratos amostrados (tabela 1); Tillandsia recurvata (Bromeliaceae) com VIE $=19,6$ e nota média de 1,95 , ocorrendo em $57 \%$ dos forófitos e $41 \%$ dos estratos; Pleopeltis pleopeltifolia (Polypodiaceae), com VIE de 18,7 e nota média 2,08 , tendo ocorrido em $57 \%$ dos forófitos e $27 \%$ dos estratos; e Pleopeltis squalida (Polypodiaceae) com VIE de 10,3 e nota média de 2,42, ocorrendo em $20 \%$ dos forófitos e $17 \%$ dos estratos. Estas quatro espécies foram responsáveis por $68,6 \%$ do VIE obtido na amostra, podendo ser consideradas dominantes no ambiente epifítico da área estudada. As quatro espécies tiveram indivíduos registrados em todos os sítios analisados.

O sítio RIA apresentou a maior riqueza, sendo encontradas 18 espécies (tabela 2), e o maior VA entre todos os sítios (2473); o índice de Shannon $\left(H^{\prime}\right)$ estimado foi de 2,159 , a equabilidade $(J)$ igual a 0,747 e o índice de riqueza de Margalef (d) foi de 2,180. Nesse sítio Tillandsia tricholepis (Bromeliaceae) foi a espécie que apresentou maior valor de importância epifítica (VIE $=21,2$ ), tendo ocorrido em $97 \%$ dos forófitos e $91 \%$ dos estratos amostrados, obtendo nota média de 2,11. Tillandsia recurvata (Bromeliaceae) foi a segunda espécie mais importante (VIE $=19,9$ e nota média $=$ 2,0 ), sendo amostrada em $99 \%$ dos forófitos e $90 \%$ dos estratos. A terceira espécie mais importante desse sítio, com VIE $=14,7$ e nota média de 2,19, foi Pleopeltis pleopeltifolia (Polypodiaceae), tendo sido observada em $72 \%$ dos forófitos e $61 \%$ dos estratos. Pleopeltis squalida (Polypodiaceae) com VIE $=13,5$ e nota média de 2,42 
Tabela 2. Espécies epifíticas dos sítios estudados na Floresta Nacional de Ipanema, SP, classificadas segundo o valor de importância epifítica. $(\mathrm{nr}=$ número absoluto de ocorrências nos estratos; $\mathrm{FAr}=$ freqüência absoluta nos estratos; ni = número absoluto de ocorrências nos indivíduos forofíticos; $\mathrm{FAi}$ = freqüência absoluta nos indivíduos forofíticos; $\mathrm{vt}$ = valor total, soma das estimativas de abundância; VIE = valor de importância epifítico; nota = nota média obtida).

Table 2. Epiphytic species of the studied sites in the Ipanema National Forest, São Paulo state, ordered by the epiphytic importance value. $(\mathrm{nr}=$ absolute number of occurrences in strata; $\mathrm{FAr}=$ absolute frequency in the strata; $\mathrm{ni}=$ absolute number of occurrences in phorophytic individuals; $\mathrm{FAi}=$ absolute frequency in phorophytic individuals; $\mathrm{vt}=$ total value, sum of estimates of abundance; VIE = epiphytic importance value; nota = average score).

\begin{tabular}{|c|c|c|c|c|c|c|c|c|}
\hline Sítios & Espécies & $\mathrm{nr}$ & $\mathrm{FAr}$ & ni & FAi & vt & VIE & nota \\
\hline \multirow{18}{*}{$\begin{array}{l}\text { Remanescente } \\
\text { Isolado/Alterado } \\
\text { RIA }\end{array}$} & Tillandsia tricholepis & 245 & 90.7 & 87 & 96.7 & 516 & 21.2 & 2.11 \\
\hline & Tillandsia recurvata & 242 & 89.6 & 89 & 98.9 & 485 & 19.9 & 2.00 \\
\hline & Pleopeltis pleopeltifolia & 164 & 60.7 & 65 & 72.2 & 359 & 14.7 & 2.19 \\
\hline & Pleopeltis squalida & 136 & 50.4 & 50 & 55.6 & 329 & 13.5 & 2.42 \\
\hline & Tillandsia stricta & 151 & 55.9 & 75 & 83.3 & 273 & 11.2 & 1.81 \\
\hline & Epiphyllum phyllanthus & 69 & 25.6 & 39 & 43.3 & 133 & 5.5 & 1.93 \\
\hline & Rhipsalis cereuscula & 37 & 13.7 & 26 & 28.9 & 94 & 3.9 & 2.04 \\
\hline & Microgramma squamulosa & 39 & 14.4 & 15 & 16.7 & 89 & 3.7 & 2.28 \\
\hline & Rhipsalis teres & 14 & 5.2 & 11 & 12.2 & 36 & 1.5 & 2.57 \\
\hline & Cereus alacriportanus & 18 & 6.7 & 9 & 10.0 & 33 & 1.4 & 1.83 \\
\hline & Lepismium warmingianum & 17 & 6.3 & 10 & 11.1 & 30 & 1.2 & 1.76 \\
\hline & Lepismium cruciforme & 9 & 3.3 & 7 & 7.8 & 23 & 0.9 & 2.56 \\
\hline & Aechmea distichantha & 10 & 3.7 & 7 & 7.8 & 13 & 0.5 & 1.30 \\
\hline & Lepismium lumbricoides & 5 & 1.9 & 4 & 4.4 & 8 & 0.3 & 1.60 \\
\hline & Philodendron bipinnatifidum & 7 & 2.6 & 6 & 6.7 & 8 & 0.3 & 1.14 \\
\hline & Epidendrum sp. & 3 & 1.1 & 2 & 2.2 & 4 & 0.2 & 1.33 \\
\hline & Aechmea apocalyptica & 1 & 0.4 & 1 & 1.1 & 2 & 0.1 & 2.00 \\
\hline & Oeceoclades maculata & 1 & 0.4 & 1 & 1.1 & 2 & 0.1 & 2.00 \\
\hline \multirow{7}{*}{$\begin{array}{l}\text { Floresta } \\
\text { Avançada/Borda } \\
\text { FAB }\end{array}$} & Tillandsia recurvata & 86 & 31.9 & 58 & 64.4 & 157 & 43.0 & 1.83 \\
\hline & Tillandsia tricholepis & 90 & 33.3 & 40 & 44.4 & 128 & 35.1 & 1.42 \\
\hline & Pleopeltis pleopeltifolia & 38 & 14.1 & 31 & 34.4 & 55 & 15.1 & 1.45 \\
\hline & Microgramma squamulosa & 6 & 2.2 & 5 & 5.6 & 12 & 3.3 & 2.00 \\
\hline & Tillandsia stricta & 7 & 2.6 & 6 & 6.7 & 7 & 1.9 & 1.00 \\
\hline & Tradescantia albiflora & 2 & 0.7 & 2 & 2.2 & 4 & 1.1 & 2.00 \\
\hline & Aechmea bromeliifolia & 1 & 0.4 & 1 & 1.1 & 2 & 0.5 & 1.00 \\
\hline \multirow{13}{*}{$\begin{array}{l}\text { Floresta } \\
\text { Avançada/Interior } \\
\text { FAI }\end{array}$} & Pleopeltis pleopeltifolia & 97 & 35.93 & 57 & 63.3 & 208 & 40.1 & 2.39 \\
\hline & Rhipsalis cereuscula & 78 & 28.89 & 50 & 55.6 & 184 & 35.5 & 1.73 \\
\hline & Microgramma squamulosa & 15 & 5.56 & 9 & 10.0 & 31 & 6.0 & 2.07 \\
\hline & Lepismium warmingianum & 9 & 3.33 & 6 & 6.7 & 21 & 4.0 & 2.33 \\
\hline & Tillandsia tricholepis & 13 & 4.81 & 12 & 13.3 & 17 & 3.3 & 1.31 \\
\hline & Pleopeltis squalida & 6 & 2.22 & 4 & 4.4 & 14 & 2.7 & 2.33 \\
\hline & Epiphyllum phyllanthus & 7 & 2.59 & 6 & 6.7 & 13 & 2.5 & 1.30 \\
\hline & Lepismium cruciforme & 6 & 2.22 & 4 & 4.4 & 13 & 2.5 & 2.17 \\
\hline & Tillandsia recurvata & 7 & 2.59 & 6 & 6.7 & 10 & 1.9 & 1.43 \\
\hline & Anthurium $\mathrm{sp}$ & 2 & 0.74 & 2 & 2.2 & 3 & 0.6 & 1.50 \\
\hline & Epidendrum sp. & 2 & 0.74 & 2 & 2.2 & 2 & 0.4 & 1.00 \\
\hline & Oeceoclades maculata & 1 & 0.37 & 1 & 1.1 & 2 & 0.4 & 2.00 \\
\hline & Cereus alacriportanus & 1 & 0.37 & 1 & 1.1 & 1 & 0.2 & 1.00 \\
\hline
\end{tabular}


foi observada em $56 \%$ dos forófitos e $50 \%$ dos estratos, sendo considerada a quarta espécie mais importante para o sítio RIA. A quinta espécie de maior importância, com VIE $=11,2$ e nota média de 1,81, foi Tillandsia stricta (Bromeliaceae) que esteve presente em $83 \%$ dos forófitos e $56 \%$ dos estratos amostrados. Rhipsalis teres e Lepismium cruciforme (Cactaceae) apresentaram as maiores notas médias, 2,57 e 2,56, respectivamente.

$\mathrm{O}$ sítio FAB apresentou menor riqueza, com sete espécies (tabela 2). Nesse sítio, o valor absoluto (VA) foi igual a 365 , o índice de Shannon $\left(H^{\prime}\right)$ estimado para a borda foi de 1,270 , a equabilidade $(J)$ igual a 0,652 e a riqueza de Margalef (d) foi de 1,017. Tillandsia recurvata (Bromeliaceae) destacou-se como a espécie mais importante no sítio FAB, com valor de importância epifítica (VIE) equivalente a 43,0 e nota média igual a 1,83; esta espécie também ocorreu em $64 \%$ dos forófitos e $32 \%$ dos estratos amostrados. A segunda espécie mais importante para este sítio, Tillandsia tricholepis (Bromeliaceae), foi amostrada em $44 \%$ dos forófitos e $33 \%$ dos estratos, obtendo VIE igual a 35,1 e nota média de 1,42. Essa duas espécies foram responsáveis por um VIE igual a 78,1 tornando a família Bromeliaceae a mais importante para o sítio FAB. Pleopeltis pleopeltifolia (Polypodiaceae), presente em $34 \%$ dos forófitos e $14 \%$ dos estratos, teve VIE igual a 15,1 e nota média igual a 1,45 , sendo considerada a terceira espécie mais importante. Microgramma squamulosa (Polypodiaceae) e Tradescantia albiflora (Commelinaceae) obtiveram nota média igual a dois, as maiores notas para o sítio FAB.

No sítio FAI foram amostradas 13 espécies (tabela $2)$, com VA $=519$, o índice de Shannon $\left(H^{\prime}\right)$ estimado foi de 1,587 , a equabilidade $(J)$ de 0,618 e a riqueza de Margalef(d) foi de 1,919. Neste sítio, a espécie de maior destaque foi Pleopeltis pleopeltifolia (Polypodiaceae), que obteve VIE igual a 40,1 e nota média igual a 2,39, estando presente em $63 \%$ dos forófitos e 36\% dos estratos. Rhipsalis cereuscula (Cactaceae) foi a segunda espécie mais importante neste sítio, com VIE igual a 35,5 e nota média de 1,73 , ocorrendo em $56 \%$ dos forófitos e $29 \%$ dos estratos. Lepismium warmingianum (Cactaceae) e Pleopeltis squalida (Polypodiaceae) obtiveram a segunda maior nota média $(2,33)$, embora tenham apresentado diferentes valores de importância epifítica (VIE $=4,0$ e VIE $=2,7$, respectivamente). A família Polypodiaceae merece destaque no sítio FAI por apresentar $\mathrm{VIE}=48,8$.

O teste $\mathrm{T}$ (Student), com base na somatória das notas obtidas pelas espécies, entre os sítios estudados, evidenciou que existe diferença significativa entre as espécies epifíticas que ocorrem nos sítios RIA e FAB $\left(\mathrm{T}_{\text {calc }}=2,59 ; \mathrm{T}_{\text {crit }}=2,02\right.$ e $\left.P=0,007\right)$ e entre os sítios RIA e FAI $\left(\mathrm{T}_{\text {calc }}=2,34 ; \mathrm{T}_{\text {crit }}=2,02\right.$ e $\left.P=0,012\right)$ e não mostrou diferença significativa entre os sítios FAB e FAI $\left(\mathrm{T}_{\text {calc }}=0,46 ; \mathrm{T}_{\text {crit }}=2,02\right.$ e $\left.P=0,321\right)$, o mesmo resultado foi encontrado quando aplicado o teste de Kolmogorov-Smirnov apresentado diferença significativa entre os sítios RIA e FAB ( $P=0,0011)$, entre RIA e FAI $(P=0,0290)$ e não apresentando diferença significativa entre os sítios FAB e FAI $(P=0,3037)$. O coeficiente de similaridade de Jaccard, aplicado à amostra, revelou existir $63 \%$ de similaridade entre os sítios RIA e FAI e $25 \%$ de similaridade entre esses sítios e o sítio FAB. O diagrama de Whittaker (figura 2), com base no VIE (Log10) caracteriza a distribuição da abundância das espécies epifíticas nos diferentes sítios da Floresta Nacional de Ipanema; o eixo Y representa o logaritmo

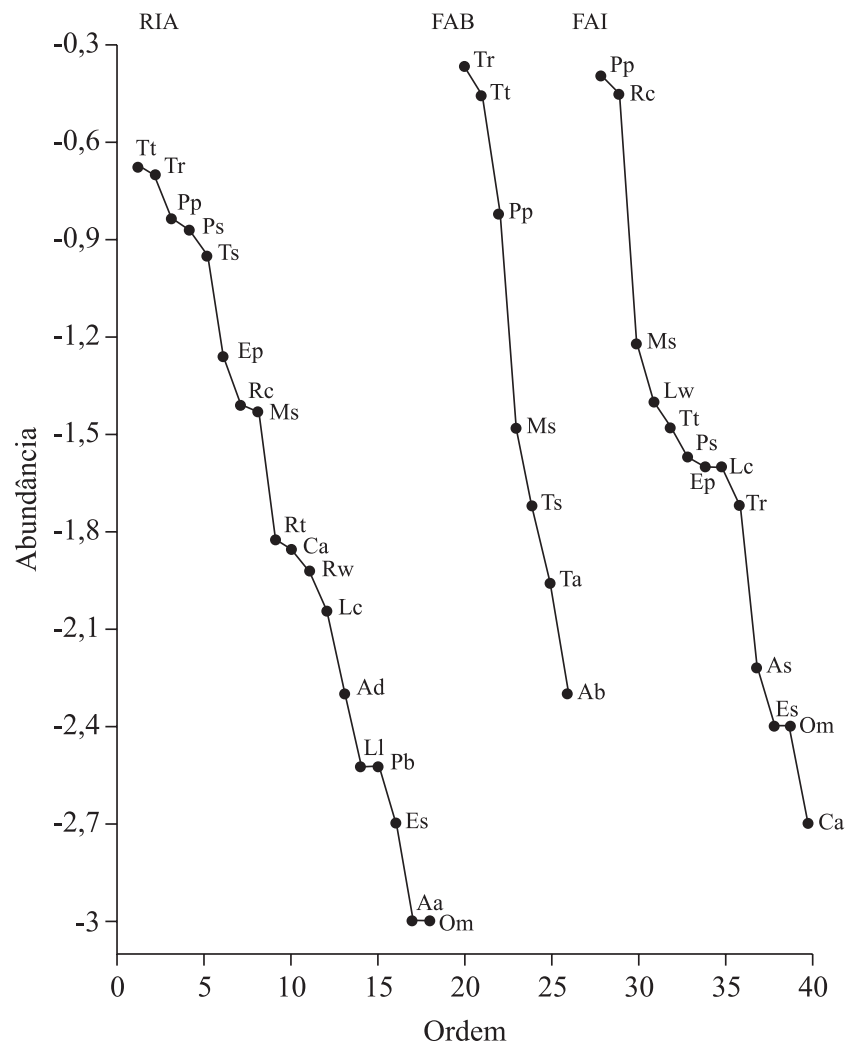

Figura 2. Diagrama de Whittaker entre os sítios RIA remanescente isolado/alterado, FAB - floresta avançada/borda e FAI - floresta avançada/interior em Floresta Estacional Semidecidual, Floresta Nacional de Ipanema, Iperó, São Paulo.

Figure 2. Whittaker diagram among the sites RIA - forest remnant isolated/modified, FAB - advanced forest/edge, and FAI - advanced forest/inside, on the Semideciduous Forest of the Ipanema National Forest, Iperó, São Paulo state. 
do valor de importância epifítica de cada espécie e o eixo $\mathrm{X}$, o rol das espécies em ordem decrescente do valor de importância (VIE).

A distribuição epifítica nos estratos, observando todos os sítios, em termos de valores absolutos, evidenciou o fuste alto como estrato com maior abundância epifítica, apresentando um valor absoluto (VA) igual a 1.492, seguido pela copa com VA igual a 1.145 e fuste baixo com VA igual a 648. No entanto, os testes T e KolmogorovSmirnov aplicados a estes dados não demonstraram diferenças significativas $(P>0,05)$ entre os estratos. Esse mesmo padrão de distribuição vertical das espécies epifíticas nos estratos foi apresentado em todos os sítios, quando analisados individualmente.

\section{Discussão}

A riqueza específica observada, para todos os sítios, pode ser considerada baixa, principalmente quando comparada com a de outros estudos realizados em formações florestais mais úmidas, como em Floresta Ombrófila Densa, como os de Hertel (1950) - 101 espécies, Schütz-Gatti (2000) - 175 espécies, Petean (2003) - 97 espécies, e Kersten (2006) - 143 espécies. $\mathrm{O}$ mesmo ocorre em relação a estudos realizados em Floresta Ombrófila Mista, como os de Dittrich et al. (1999) - 72 espécies, Kersten \& Silva (2002) - 49 espécies, e Borgo \& Silva (2003) - 96 espécies.

Quando comparada com o mesmo tipo formação florestal (Floresta Estacional Semidecidual) fica abaixo dos estudos realizados por Rogalski \& Zanin (2003) que encontraram 70 espécies, e de Giongo \& Waechter (2004) que amostraram 57 espécies. No entanto, assemelha-se aos estudos realizados por Aguiar et al. (1981) que amostraram 17 espécies, de Dislich \& Mantovani (1998) com 34 espécies, e de Borgo et al. (2002), com 32 espécies. Pode-se notar, também, semelhança com os resultados de Bataghin et al. (2008) que observaram 18 espécies epífitas em Floresta Ombrófila Mista (RS), Waechter (1992) que amostrou 24 espécies epifíticas em restinga no Taim(RS), e de Piliackas et al. (2000) que encontraram 26 espécies em um manguezal em Ubatuba (SP).

Todas as famílias encontradas na área estudo estão entre as mais abundantes mundialmente como epífitas (Benzing 1990). A família Orchidaceae, mesmo sendo a mais rica mundialmente (Madison 1977, Kress 1986, Benzing 1990), nos neotrópicos (Gentry \& Dodson 1987) e no Brasil (Kersten 2006), apresentou apenas duas espécies e um número baixo de ocorrências na área de estudo, o que pode ser atribuído ao clima seco da região, bem como às alterações ambientais antrópicas. A família Cactaceae, apesar de ser responsável por menos de 0,5\% das espécies epifíticas mundiais (Madison 1977, Benzing 1990) e por cerca de 3\% das espécies epifíticas brasileiras (Kersten 2006), foi a mais diversa, sendo responsável por 33\% das espécies da área, seguida pela família Bromeliaceae (29\%). O endemismo neotropical de Bromeliaceae e Cactaceae (Dislich \& Mantovani 1998) pode ser responsável por estes números. O gênero Rhipsalis (Cactaceae) tem seu centro de dispersão no sul e sudeste brasileiros (Scheinvar 1985).

A classificação em categorias ecológicas segundo as formas de vida evidenciou o predomínio de holoepífitos característicos. A mesma predominância foi observado em Floresta Estacional Semidecidual por Pinto et al. (1995), Kersten \& Kuniyoshi (2009), Dislich \& Mantovani (1998) e Rogalski \& Zanin (2003) e em outras formações florestais como a Floresta Ombrófila Mista (Dittrich et al. 1999) e áreas de restinga (Waechter 1992, Kersten \& Silva 2001).

No sítio RIA predominam as Bromeliaceae e Polypodiaceae com quase $85 \%$ do valor de importância epifítica, evidenciando a importância dessas famílias não só para esse sítio, mas também para toda a área de estudo. Essas duas famílias apresentaram maiores valores de importância em vários estudos brasileiros com epífitas (Kersten \& Silva 2002, Gonçalves \& Waechter 2002, Giongo \& Waechter 2004). Nesse sítio, caracterizado pela presença de forófitos isolados, às vezes formando cobertura contínua do dossel, foi registrado o maior número de espécies $\left(H^{\prime}=2,15\right)$ e o maior valor de abundância dentre todos os sítios amostrados. A presença de forófitos de grande porte, mesmo que isolados ou em remanescentes alterados pela ação antrópica, são essenciais para a comunidade epifítica que na maioria das vezes requer acúmulo de solo suspenso e podem servir como fonte de propágulos para o crescimento de epífitas em outros forófitos (Wolf 2005). Tal importância é destacada por Gonçalves \& Waechter (2002) que encontraram 77 espécies epifíticas $\left(H^{\prime}=3,519\right)$ estudando forófitos isolados de Ficus organensis (Miq.) Miq., e concluíram que tais forófitos apresentam situação favorável ao epifitismo mesmo considerando as condições ambientais mais extremas a que os epífitos estão submetidos, como maior luminosidade, maior incidência de ventos e a ação dos seres humanos.

$\mathrm{O}$ sítio $\mathrm{FAB}$, borda de uma floresta secundária em estágio avançado de restauração e limítrofe a uma área cultivada, apresentou o menor número de espécies epifíticas $\left(H^{\prime}=1,27\right)$ e também o menor valor absoluto, entre todos os sítios estudados. Nesse sítio, a presença de fatores abióticos como a maior velocidade 
de vento, o aumento da luminosidade e da temperatura e a diminuição da umidade relativa (Murcia 1995), exercem influência direta na diversidade epifítica. Outro aspecto importante nesse sítio foi a grande participação da família Bromeliaceae na composição epifítica, com $80 \%$ do valor de importância epifítico, destacando-se a predominância do gênero Tillandsia (tabela 2), que geralmente tem grande resistência ao déficit hídrico (Benzing 1990, Kersten 2006). Benzing (1976) ainda classifica as Tillandsia como espécies que apresentam caracteres xeromórficos em nível foliar. Segundo Bonnet \& Queiroz (2006), as espécies do gênero Tillandsia apresentaram mais indivíduos, ocupando mais espécies forofíticas e tiveram maiores freqüências em estágios sucessionais iniciais, nos quais a luminosidade e a temperatura são elevadas e a umidade é baixa. Além disso, das sete espécies encontradas quatro são classificadas por Kersten \& Kuniyoshi (2009) como espécies pioneiras (iniciais ou tardias); soma-se a esse grupo Tillandsia tricholepis que apresenta características semelhantes às citadas por esses autores. Os efeitos de borda, o período de tempo demandado pelas epífitas para o aumento da riqueza e o estágio sucessional da floresta contribuem de forma fundamental para o pequeno número de espécies epifíticas e para a dominância de poucas espécies, especialmente as do gênero Tillandsia.

Outro fator relevante que pode ter contribuído para a ocorrência de poucas espécies no sítio FAB, é o predomínio de forófitos da espécie Lonchocarpus muehlbergianus Hassl. (Fabaceae), espécie forofítica com características que podem dificultar o estabelecimento de espécies epifíticas, como, por exemplo, o pouco acúmulo de solo suspenso. Em adição a isso, a diversidade de epífitas tem sido associada à diversidade de forófitos (Barthlott et al. 2001, Wolf 2005, Cascate-Marín et al. 2006), de modo que o predomínio de forófitos (67\%) da espécie citada anteriormente no sítio FAB, exerce um papel importante na composição e na diminuição da riqueza da comunidade epifítica desse sítio.

No sítio FAI, destacou-se a família Polypodiaceae com quase $50 \%$ do valor de importância epifítica (tabela 2). Kersten \& Silva (2002), estudando a Floresta Ombrófila Mista Aluvial do Rio Barigüi, destacaram essa mesma família como a mais importante da área, responsável por $66 \%$ do valor de importância epifítica. As Cactaceae também são dignas de nota no sítio de interior por apresentarem quase $45 \%$ do VIE do sítio. Certamente a capacidade de armazenamento de água (Coutinho 1962) e o endemismo neotropical (Dislich \& Mantovani 1998, Scheinvar 1985) são responsáveis pela grande presença dessa família.
A maior umidade relativa do ar é comumente observada no interior da floresta e decresce nas áreas abertas devido ao aumento da temperatura do ar e da velocidade do vento (Schulz 1960, Lee 1987). O maior número de espécies epifíticas do sítio $\mathrm{FAI}\left(H^{\prime}=1,58\right)$ em relação ao sítio $\mathrm{FAB}$, bem como o maior valor absoluto, pode ser atribuído à diminuição do chamado efeito de borda, que é responsável, entre outras coisas, pela redução da umidade, fator limitante à comunidade epifítica. $\mathrm{O}$ estresse hídrico é uma das maiores dificuldades para a sobrevivência acima do solo (Laube \& Zotz 2003). O sítio FAI, caracterizado como uma área de floresta secundária em estágio avançado de regeneração e localizado a 300 metros da borda externa da floresta, apresenta características originais de Floresta Estacional Semidecidual, a qual, segundo Dettke et al. (2008), proporciona um dossel fechado favorecendo algumas espécies de Polypodiaceae, Cactaceae e Araceae, que toleram ou exigem baixas taxas de luminosidade.

Os testes $\mathrm{T}$ e Kolmogorov-Smirnov aplicados à distribuição vertical das epífitas vasculares entre os estratos não apresentaram variação significativa $(P>0,05)$, tanto quando considerada toda a comunidade epifítica quanto ao analisar os sítios individualmente. As epífitas distribuem-se de forma irregular ao longo dos forófitos, apresentando variação vertical, tanto no número de indivíduos como de espécies encontradas (Steege \& Cornelissen 1989, Brown 1990, Waechter 1992).

Alguns fatores que podem influenciar os padrões de distribuição e abundância de epífitas vasculares nas florestas tropicais relacionam-se às variações de luminosidade e umidade estabelecidas entre o dossel e o solo, além da arquitetura, porte e características da casca externa dos forófitos, entre outros (Luttge 1989, Steege \& Cornelissen 1989). Em todos os sítios amostrados, o fuste alto apresentou o maior valor de abundância epifítica, seguido pela copa e pelo fuste baixo. O maior valor de abundância observado no fuste alto, em relação ao fuste baixo, parece indicar que a passagem do ambiente terrícola para o epifítico foi realmente uma migração em busca de luz (Benzing 1990), muito embora, o estresse hídrico seja o principal desafio para as epífitas (Kersten \& Silva 2002).

Embora a dinâmica de populações epífitas seja pouco considerada em estudos científicos (Kersten 2006), sabe-se que a densidade de seus indivíduos e espécies está inversamente correlacionada ao grau de alteração dos ecossistemas florestais (Bonnet \& Queiroz, 2000). No entanto, essa tendência não foi plenamente observada na área de estudo. O pequeno número de espécies epifíticas encontrado em toda a área da Floresta 
Nacional de Ipanema pode ser atribuído ao longo período de interferências humanas sobre a floresta (Ibama 2003). Apesar disso, o maior número de espécies e indivíduos, bem como a diferença estatística encontradas no sítio RIA, em relação aos sítios FAB e FAI, remete à importância dos remanescentes florestais que sofrem pressão antrópica ou mesmo de árvores isoladas que servem como forófitos às comunidades relictuais de epífitas vasculares. Bonnet et al. (2009), observou relação positiva entre a riqueza de epífitas e o tamanho dos forófitos mesmo quando esses encontravam-se isolados na paisagem ou em áreas de criação de bovinos sob as árvores. Esse aumento da riqueza é observado nesse estudo pelo maior número de indivíduos epifíticos no sítio RIA.

O diagrama de Whittaker, que pode ser observado na figura 2, representa a forma como a abundância se distribui entre as espécies e esta apresentou-se característica para cada sítio estudado, ilustrando a diferença entre as diversidades e abundância de cada sítio. No sítio RIA, o decréscimo da curva indica a maior diversidade do sítio e a distribuição dos pontos na curva sugere uma maior equidade do valor de importância epifítico entre as espécies. Esse tipo de distribuição ocorre, geralmente, em comunidades com poucas espécies em um ambiente homogêneo e que, em muitos casos as espécies exercem funções similares, competindo por um mesmo e importante recurso (Martins \& Santos 1999) ou pelo lento processo de restabelecimento das epífitas (Engwald et al. 2000, Barthlott et al. 2001) dada as alterações ambientais na área (Ibama 2003). No sítio FAB, a curva indica a abundância elevada de algumas espécies, que diminui de maneira rápida e constante nas outras espécies. Essa distribuição normalmente é observada em comunidades muito simples e com poucas espécies, as quais competem de modo forte e hierárquico sob pressão de um fator predominante. O decréscimo da curva no sítio FAI mostra uma situação em que poucas espécies epifíticas apresentam grande abundância e a maioria das espécies apresenta abundância muito pequena. Essa forma de distribuição tem sido observada em comunidades simples em ambientes relativamente restritivos, mas ainda não saturados, onde predominam poucos fatores muito importantes (Martins \& Santos 1999). As formas de distribuição observadas nos sítios FAB e FAI, em que poucas espécies são muito abundantes e a maioria das espécies tem abundância pequena, são normalmente denominadas de modelos de pré-esvaziamento de nichos (May 1975).

A pequena riqueza de epífitas vasculares na Floresta Nacional de Ipanema é característica de florestas que sofrem interferência antrópica (Bataghin et al. 2008). Tal declínio de riqueza é relatado por Barthlott et al. (2001) que observou a redução no número de espécies em decorrência do aumento do grau de interferência humana. A concentração de espécies nas famílias Bromeliaceae, Cactaceae e Polypodiaceae (que resistem a ambientes com maior luminosidade e menor umidade) foi observada em um remanescente alterado de Floresta Estacional Semidecidual por Dettke et al. (2008). Na Flona de Ipanema, essas mesmas famílias concentraram o maior número de espécies e os maiores valores de importância epifítica, confirmando as alterações ambientais existentes na área de estudo.

Embora as análises estatísticas apontem diferenças significativas entre os sítios RIA e FAB e entre os sítios RIA e FAI, não existe diferença entre os sítios FAB e FAI, sítios estes de borda e interior da floresta secundária em regeneração. É interessante notar a maior abundância, riqueza e diversidade no sítio RIA, cuja diferença em relação aos outros dois sítios ressalta a importância de remanescentes alterados ou até mesmo forófitos isolados para a comunidade epifítica vascular. O sítio RIAé uma área com forófitos de maior porte isolados, onde, emalguns casos, as copas formam uma cobertura do dossel. Diante disso, os dados não confirmam a hipótese da existência de diferenças entre os sítios, embora estes representem ambientes distintos, indicando a possibilidade de que a comunidade epifítica vascular esteja se restabelecendo lentamente após o longo histórico de perturbações da área. A ocorrência de espécies epifíticas comuns aos ambientes antrópicos (Bataghin et al. 2008, Dettke et al 2008) e a composição de epífitas muito semelhante entre os sítios analisados também pode ser considerada uma evidência da degradação ambiental da área estudada. Engwald et al. (2000), estudando diversidade de epífitas, distribuição espacial e dinâmica de processos na vegetação epifítica vascular em diferentes tipos de florestas, relataram a perda de $55 \%$ das espécies em áreas alteradas e/ou de vegetação secundária; em adição, a ausência de complexidade estrutural dessas florestas faz com que a comunidade epifítica, além de ser pouco diversa, demande um tempo muito maior para seu (re)estabelecimento, seja pela ausência de forófitos de maior porte, seja pelas condições microclimáticas não favoráveis.

Cabe destacar que a Flona de Ipanema é aberta à visitação pública e que em todos os sítios existiam sinais de trilhas, o que permite supor a possibilidade de coleta ilegal de espécies epifíticas, especialmente as orquídeas e bromélias. As florestas tropicais são ameaçadas não apenas por grandes desmatamentos, mas também por uma 
série de fatores menos evidentes, que levam à degradação progressiva de sua estrutura e de sua diversidade. Dentre esses fatores, Ditt (2002) destaca a coleta de espécies usadas na ornamentação, como Orchidaceae e Bromeliaceae, tipo de ação antrópica que pode levar à redução do número de indivíduos, contribuindo para a diminuição da diversidade biológica e a degradação ambiental.

Para Hietz (1999), o fato das epífitas apresentarem crescimento lento e alta sensibilidade às variações climáticas torna-as mais vulneráveis, e isso se agrava com a perda de florestas, especialmente das árvores de maior porte, o que, automaticamente, causa a perda da comunidade epifítica, uma vez que esta depende diretamente das árvores para se instalar. Os dados deste trabalho ressaltam a importância dos fatores ambientais ao atuarem de forma limitante sobre a comunidade epifítica, a qual, na área de estudo, sofre influência direta de fatores antrópicos, como a remoção da vegetação, a degradação da floresta, a criação de bordas artificiais e as perturbações humanas nas áreas florestais e adjacentes, influenciando a diversidade e a distribuição da comunidade epifítica vascular dos três sítios na Floresta Nacional de Ipanema. Medidas de proteção às florestas, mesmo que alteradas pela ação antrópica, preservação das árvores de maior porte (muito exploradas comercialmente) e o não incentivo ao comércio de espécies ornamentais que degradam a riqueza e diversidade das florestas, devem ser adotadas em prol da conservação de epífitas vasculares.

Agradecimentos - Os autores agradecem a administração da Floresta Nacional de Ipanema por permitir a realização dessa pesquisa e pela hospitalidade e atenção durante esse trabalho. Aos pesquisadores Prof. Dr. Jefferson Prado e Ms. Pedro Bond Schwartsburd pela contribuição na identificação das espécies. Ao Prof. Dr. Luciano Elsinor Lopes pelas contribuições e análises estatísticas. A um assessor anônimo pelos valiosos comentários e sugestões a esse artigo. A Fundação de Amparo a Pesquisa do Estado de São Paulo - Fapesp. Ao Laboratório de Análise e Planejamento Ambiental e ao Programa de Pós Graduação em Ecologia e Recursos Naturais da Universidade Federal de São Carlos.

\section{Referências bibliográficas}

AGUIAR, L.W., CITADINE-ZANETTE, V., MARTAU, L. \& BACKES, A. 1981. Composição florística de epífitos vasculares numa área localizada no município de Montenegro e Triunfo, Rio Grande do Sul, Brasil. Iheringia (Série Botânica) 28:55-93.
BARTHLOTT, W., SCHMIT-NEUERBURG, V., NIEDER, J. \& ENGWALD, S. 2001. Diversity and abundance of vascular epiphytes: a comparison of secondary vegetation and primary montane rain forest in the Venezuelan Andes. Plant Ecology 152:145-156.

BATAGHIN, F.A., FIORI, A. \& TOPPA, R.H. 2008. Efeito de borda sobre epífitas vasculares em Floresta Ombrófila Mista, Rio Grande do Sul, Brasil. O Mundo da Saúde 32:329-338.

BENZING, D.H. 1976. Bromeliad trichomes: structure, function, and ecological significance. Selbyana 1: 330-348.

BENZING, D.H. 1990. Vascular epiphytes. Cambridge University Press, Cambridge.

BONNET, A., LAVORANTI, O.J. \& CURCIO, G.R. 2009. Relações de epífitos vasculares com fatores ambientais no corredor de biodiversidade araucária, Paraná. In Anais do IX Congresso de Ecologia do Brasil - Ecologia e o futuro da biosfera. São Lourenço, v.1, p.1-4.

BONNET, A. \& QUEIROZ, M.H. 2006. Estratificação vertical de bromélias epifíticas em diferentes estádios sucessionais da Floresta Ombrófila Densa, Ilha de Santa Catarina, Santa Catarina, Brasil. Revista Brasileira de Botânica 29:217-228.

BONNET, A. \& QUEIROZ, M.H. 2000. Considerações sobre bromélias epifíticas como indicadores de florestas degradadas. Unidade de Conservação ambiental Desterro, Ilha de Santa Catarina. In Anais do II Congresso Brasileiro de Unidades de Conservação. Rede Nacional Pró Unidades de Conservação e Fundação o Boticário de Proteção à Natureza, Campo Grande, v.2, p.217-221.

BORGO, M. \& SILVA, S.M. 2003. Epífitos vasculares em fragmentos de Floresta Ombrófila Mista, Curitiba, Paraná, Brasil. Revista Brasileira de Botânica 26:391-401.

BORGO, M., SILVA, S.M. \& PETEAN, M.P. 2002. Epífitos vasculares em um remanescente de floresta estacional semidecidual, município de Fênix, PR, Brasil. Acta Biologica Leopoldensia 24:121-130.

BROWN, A.D. 1990. El epifitismo en las selvas montanas del Parque Nacional "El Rey", Argentina: composición florística y patrón de distribución. Revista de Biologia Tropical 38:155-166.

BRUMMITT, R.K. \& POWELL, C.E. 1992. Authors of plant names. ${ }^{\text {st }}$ ed., Royal Botanic Gardens, Kew.

CALLAWAY, R.M., BROOKER, R.W., CHOLER, P., KIKVIDZE, Z., LORTIE, C.J., MICHALET, R., PAOLINI, L., PUGNAIRE, F.I., NEWINGHAM, B., ASCHEHOUG, E.T., ARMAS, C., KIKODZE, D.E. \& COOK, B.J. 2002. Positive interactions among alpine plants increase with stress. Nature 417:844-848.

CASCANTE-MARÍN, A., WOLF, J.H.D., OOSTERMEIJER, J.G.B., DEN NIJS, J.C.M., SANAHUJA O. \& DURÁNAPUY, A. 2006. Epiphytic bromeliad communities in secondary and mature forest in a tropical premontane area. Basic Applied Ecology 7:520-532. 
COUTINHO, L.M. 1962. Contribuição ao conhecimento da ecologia da mata pluvial tropical. Boletim da Faculdade de Ciências e Letras da Universidade de São Paulo, Botânica 18:11-219.

DETTKE, G.A., ORFRINI,A.C.\& MILANEZE-GUTIERRE, M.A. 2008. Composição florística e distribuição de epífitas vasculares em um remanescente alterado de Floresta Estacional Semidecidual no Paraná, Brasil. Rodriguésia 59:859-872.

DISLICH, R. \& MANTOVANI, W. 1998. Flora de epífitas vasculares da Reserva da Cidade Universitária "Armando de Salles Oliveira" (São Paulo, Brasil). Boletim de Botânica da Universidade de São Paulo 17:61-83.

DITT, E.H. 2002. Fragmentos florestais do portal do Paranapanema. Annablume, São Paulo.

DITTRICH, V.A.O., KOZERA, C. \& SILVA, S.M. 1999. Levantamento florístico de epífitos vasculares no Parque Barigüi, Paraná, Brasil. Iheringia (Série Botânica) 52: 11-22.

ENGWALD, S., SCHIMIT-NEUERBURG, V. \& BARTHLOTT, W. 2000. Epiphytes in rain forest of Venezuela - diversity and dynamics of a biocenosis. In Results of worldwide ecological studies (S.W. Breckle, B. Schweizer \& U. Arndt, eds.). Proceedings of the first symposium by the AFW Foundation. Günter Heimbach, Hoheneim, p.425-434.

FÁVERO, O.A., NUCCI, J.C. \& BIASI, M. 2004. Vegetação natural potencial e mapeamento da vegetação e usos atuais das terras da Floresta Nacional de Ipanema, Iperó/SP: Conservação e gestão ambiental. RA'E GA - O Espaço Geográfico em Análise 8:55-68.

FIDALGO, O. \& BONONI, V.L.R. 1989. Técnicas de coleta, preservação e herborização de material botânico. Instituto de Botânica, São Paulo.

FONTOURA, T. 2001. Bromeliaceae e outras epífitas - estratificação e recursos disponíveis para animais na Reserva Ecológica Estadual de Jacarepiá, Rio de Janeiro. Bromélia 6:33-39.

GENTRY, A.H. \& DODSON, C.H. 1987. Diversity and biogeography of neotropical vascular epiphytes. Annals of the Missouri Botanical Garden 74:205-233.

GIONGO, C. \& WAECHTER, J.L. 2004. Composição florística e estrutura comunitária de epífitos vasculares em uma floresta de galeria na Depressão Central do Rio Grande do Sul. Revista Brasileira de Botânica 27:563-572.

GONÇALVES, C.N. \& WAECHTER, J.L. 2002. Epífitos vasculares sobre espécimes de Ficus organensis isolados no norte da planície costeira do Rio Grande do Sul: Padrões de abundância e distribuição. Acta Botanica Brasilica 16:429-441.

GRIME, J.P. 2001. Plant strategies, vegetation processes, and ecosystem properties. $2^{\text {nd }}$ ed, John Wiley, New York.
HERTEL, R.J.G. 1950. Contribuição à ecologia de flora epifítica da serra do mar (vertente oeste) do Paraná. Arquivos do Museu Paranaense 8:3-63.

HIETZ, P. 1999. Diversity and conservation of epiphytes in a changing environment. Pure and Applied Chemistry. http://uipac.org/symposia/proceedings/phuket97/hietz. html (acesso em 05/03/2009).

IBAMA. 2003. Plano de Manejo: Floresta Nacional de Ipanema, Iperó. Ministério do Meio Ambiente, Brasília.

KERSTEN, R.A. 2006. Epifitismo vascular na bacia do Alto Iguaçu, Paraná. Tese de Doutorado, Universidade Federal do Paraná, Curitiba.

KERSTEN, R.A. \& KUNIYOSHI, Y.S. 2009. Conservação das florestas na Bacia do alto Iguaçú, Paraná - Avaliação da comunidade de epífitas vasculares em diferentes estágios serais. Revista Floresta 39:51-66.

KERSTEN, R.A. \& SILVA, S.M. 2001. Composição florística e distribuição espacial de epífitas vasculares em floresta da planície litorânea da Ilha do Mel, Paraná, Brasil. Revista Brasileira de Botânica 24: 213-226.

KERSTEN, R.A. \& SILVA, S.M. 2002. Florística e estrutura do componente epifítico vascular em Floresta Ombrófila Mista Aluvial do rio Barigüi, Paraná, Brasil. Revista Brasileira de Botânica 5:259-267.

KRESS, J.W. 1986. A symposium: The biology of tropical epiphytes. Selbyana 9:1-22.

LAUBE, S. \& ZOTZ, G. 2003. Which abiotic factors limit vegetative growth in a vascular epiphyte? Functional Ecology 17:598-604.

LEE, R. 1987. Forest Microclimatology. Columbia University Press, New York.

LÜTTGE, U. 1989. Vascular epiphytes: Setting the scene. In Vascular plants as epiphites (U. Lüttge, ed.). Ecological Studies 79. Springer-Verlag, Berlin, p.1-14.

MADISON, M. 1977. Vascular epiphytes: their systematic occurrence and salient features. Selbyana 2:1-13.

MAGURRAN, A.E. 1988. Ecological diversity and its measurement. Princeton University, Princeton.

MARTINS, F.R. \& SANTOS, F.A.M. 1999. Técnicas usuais de estimativa da biodiversidade. Holos Environment 1:236-267.

MAY, R.M. 1975. Patterns of species abundance and diversity. In Ecology and evolution of communities (M.L. Cody \& J.M. Diamond, eds.). Belknap Press of the Havard University Press, Cambridge, p.81-120.

MURCIA, C. 1995. Edge effects in fragmented forests: implications for conservation. Trends in Ecology and Evolution 10:58-62.

NAEEM, S. 2003. Models of ecosystem reliability and their implication for the question of expendability. In The importance of species: perspectives on expendability and triage (P. Kareiva \& S.A. Levin, eds.). Princeton University Press, Princeton, p.109-139. 
PETEAN, M.P. 2003. Florística e estrutura dos epífitos vasculares em uma área de Floresta Ombrófila Densa Altomontana no Parque Estadual de Pico do Marumbi, Morretes, Paraná, Brasil. Dissertação de Mestrado, Universidade Federal do Paraná, Curitiba.

PILIACKAS, J.M., BARBOSA, L.M. \& CATHARINO, E.L.M. 2000. Levantamento das epífitas vasculares do manguezal do Rio Picinguaba, Ubatuba, São Paulo. In Anais do 5o Simpósio de Ecossistemas Brasileiros (S. Watanabe, ed.). Aciesp, São Paulo, v.2, p.357-363.

PINTO, A.C., DEMATTÊ, M.E.S.P. \& PAVANI, M.C.M.D. 1995. Composição florística de epífitas (Magnoliophyta) em fragmento de floresta no município de Jaboticabal, SP, Brasil. Científica 22:283-289.

PIRES, J.S.R., SANTOS, J.E. \& PIRES, A.M.Z.C.R. 2005. Gestão biorregional. Uma abordagem conceitual para o manejo de paisagens. In Faces da polissemia da paisagem: Ecologia, planejamento e percepção (J.E. Santos, F. Cavalheiro, J.S.R. Pires, C.H. Oliveira \& A.M.Z.C.R. Pires, eds.) Rima \& Fapesp, São Paulo, v.1, p.23-34.

ROGALSKI, J.M. \& ZANIN, E.M. 2003. Composição florística de epífitos vasculares no estreito de Augusto César, Floresta Estacional Decidual do Alto Uruguai, RS, Brasil. Revista Brasileira de Botânica 26:551-556.

SCHEINVAR, L. 1985. Cactáceas. Flora Ilustrada Catarinense (CACT). Herbário Barbosa Rodrigues, Itajaí.

SCHULZ, J.P. 1960. Ecological studies on rainforest in Northern Suriname. North Holland, Amsterdam.
SCHÜTZ-GATTI,A.L. 2000. O componente epifítico vascular na Reserva Natural de Salto Morato, Guaraqueçaba - PR. Dissertação de mestrado, Universidade Federal do Paraná, Curitiba.

SOTA, E.R. DE LA. 1971. El epifitismo y las pteridofitas en Costa Rica (America Central). Nova Hedwigia 21: 401-465.

STEEGE, H. \& CORNELISSEN, J.H.C. 1989. Distribution and ecology of vascular epiphytes in lowland rain forest of Guyana. Biotropica 21:331-339.

TILMAN, D. 1988. Plant strategies and dynamics and structure of plant communites. Princeton University Press, Princeton.

TILMAN, D. \& LEHMAN, C. 2001. Biodiversity, composition and ecosystem processes: theory and concepts. In The functional consequences of biodiverdity: empirical progress and theoretical extensions (A.P. Kinzig, S.W. Pacala \& D. Tilman, eds.). Princeton University Press, Princeton, p.9-41.

WAECHTER, J.L. 1992. O epifitismo vascular na planície costeira do Rio Grande do Sul. Tese de doutorado, Universidade Federal de São Carlos, São Carlos.

WAECHTER, J.L. 1998. Epifitismo vascular em uma floresta de restinga do Brasil subtropical. Revista Ciência e Natura 20:43-66.

WOLF, J.H.D. 2005. The response of epiphytes to anthropogenic disturbance of pine-oak forests in the highlands of Chiapas, Mexico. Forest Ecology and Management 212:376-393. 